\title{
A EDUCAÇÃO SUPERIOR NO CONTEXTO DA GLOBALIZAÇÃO*
}

Benício Viero Schmidt*

\section{Resumo}

Também no plano educacional o Brasil apresenta antigos dualismos que sustentam a existência da sociedade nacional. Há o caso exemplar de um sistema de pósgraduação avançadb, produtivo e formador de recursos humanos e científicos justaposto a situaçães dramáticas quanto ao estado do ensino em outros níveis. Daí resulta a adbção de políticas de crescimento de matrículas em todos os níveis, desacompanhada de correspondentes medidas relacionadas à qualidade do ensino. Na área da educação superior pública, as deformaçães são preocupantes. A reflexão aqui proposta parte de duas premissas: no país, as elites brasileiras nunca encararam a educação como um componente essencial para a consolidação de uma sociedade democrática e com projetos de poder no quadro intemacional; ao ladb da expansão de vagas, garantir qualidade é variável estratégica para determinar as possibilidades futuras de desenvolvimento das potencialidades nacionais.

Palavras-chave: expansão da universidade; democracia; qualidade.

\section{A internacionalização do ensino superior}

A concretização inexorável de uma comunidade científica e de informação de caráter global passa pela internacionalização acelerada do ensino superior. Isto abrange muitas dimensões complexas, tanto do ponto de vista conceitual, quanto operacional.

A primeira dificuldade resulta do quadro de profundos desequilíbrios econômicos, sociais e culturais entre regiões e países. A Á frica e a Á sia, por exemplo, devido à falta de oportunidades de emprego para sua mão-

* Texto recebido para publicação em agosto de 2000.

** Doutor em Ciência Política Stanford/USA. Professor do Centro de Estudos e Pesquisas da A mérica Latina e Caribe/UnB 
de-obra especializada e científica, exportam cérebros contumaz e costumeiramente para os países de grande desenvolvimento econômico e científico. A Índia é conhecido reservatório de programadores, físicos, matemáticos e médicos para os Estados Unidos. Cerca de $50 \%$ dos médicos do sistema público de saúde de N ova Y ork, por exemplo, são indianos. Os estudantes norte-americanos não investem mais tanto tempo de formação e residência médica quanto seria de desejar, dadas as oportunidades econômicas e profissionais al ternativas disponíveis.

A inda que o Brasil não tenha essa característica de exportador líquido de cérebros, o fenômeno começa a aprofundar-se. Companhias de informática dos Estados U nidos estão começando a angariar recursos humanos em nosso país, de modo avassalador, incluindo-se aí o nível técnico intermediário, que não supõe formação superior.

A certificação universitária, hoje mais do que nunca na história, é um requisito indispensável. Não tanto pelo que se apreende, mas pelo modo correto de apreender. A centralidade do conhecimento reside em percursos epistemológicos e metodológicos exaustivos e rigorosos, ancestrais roteiros obrigatórios da filosofia clássica e moderna. Saber abordar um objeto qualquer, tratá-lo nos seus componentes e formular hipóteses de desenvolvimento dos fenômenos observados requer justamente aquilo que é mais precioso na trajetória universitária. $E$ isto não é matéria a ser recolhida pela "experiência vivida", exclusivamente. Se isto fosse verdadeiro, os boêmios seriam os melhores poetas e os trapezistas de circo seriam os mel hores físicos, por exemplo!

0 equivalente a esses erros, que os estatísticos denominam de "falácia de nível equivocado", ou seja, tomar dados e informações manifestas por um nível da realidade observada como sendo aplicável a outro nível do real, está freqüentemente presente na análise política. Ele ocorre quando se confunde a função do político profissional com a do protagonista direto dos fatos políticos. São coisas distintas. 0 Partido dos Trabal hadores (PT), por exemplo, pode ser visto como um estudo de caso desse fenômeno. A história recente do PT, nas suas relações com os movimentos sociais (M ST, ON Gs etc.), ilustra bem o fenômeno. São papéis distintos no sistema político existente, daí as enormes contradições que têm surgido entre eles. Partido político que incorpora, de modo simplório, o protagonismo nunca chegará a partido político eficiente e eficaz, como o PT tem aprendido penosamente. 
Daí que, ao contrário do senso comum tão difundido pelos meios de comunicação, não basta expandir o ensino superior, mas manter sua alta e intrínseca qualidade. Caso contrário, seria a vulgarização das inutilidades em grande escala. Por isso, as dimensões centrais que compõem os atuais desequilíbrios mundiais têm de ser levadas em consideração pelo projeto de desenvolvimento da educação superior.

A oferta de educação superior tem aumentado fantasticamente, nos últimos anos, como prova de tendências inexoráveis. De 13 milhões de matrículas no mundo em 1960, passamos a cerca de 85 milhões em 1999; apesar dos obstáculos, principalmente residindo no continente africano de hoje. De outro lado, o número de pessoas que realizam seus estudos superiores fora de seu próprio país aumentou em 30\% nos últimos anos (920.000 em 1980 para 2 milhões em 1999), segundo a U nesco.

0 B rasil percorre caminho inverso, dadas as dificuldades financeiras do Estado, pois bancava 2.100 bolsas no exterior em 1995 e passou a menos de mil em 1999. Recentemente (2000), após um movimento massivo de privatização de sua infra-estrutura de serviços básicos (comunicações, energia, petróleo), o país dá início à regulamentação dos fundos públicos daí originados, com o intuito de sustentar financeiramente a expansão do sistema de ciência e tecnologia. A previsão para o exercício fiscal de 2001 é de haver disponibilidade de mais $\mathrm{R} \$ 1,5$ bilhão sobre o orçamento do sistema em termos correntes.

Por sua vez, o trajeto da expansão internacional do ensino superior está acima do controle de Estados nacionais. Também é preciso ressal tar que os crescentes desequilíbrios na distribuição mundial da qualidade e da quantidade de matrículas no ensino superior tendem a consolidar as desigual dades sociais eeconômicas em escala mundial. Garantir expansão, com qualidade, é uma variável estratégica para determinar as possi bilidades futuras de desenvolvimento da potencial idade das forças produtivas.

\section{A batalha da educação no Brasil}

Por sua parte, nos últimos anos o B rasil tem despertado para a situação histórica envolvendo déficits educacionais. Como sempre, em contextos de grandes deficiências básicas, o primeiro ataque é à disponibilidade de matrículas em todo o sistema, em todos os níveis. 
Historicamente, o B rasil tem convivido, também no plano educacional, com os vel hos dual ismos que sustentam a existência da sociedadenacional. Ou seja, componentes e subsistemas sociais extremamente atrasados na perspectiva da modernidade capital ista - ao lado de outros subsistemas típicos das sociedades capitalistas mais avançadas. M esmo em termos relativos, este tem sido o caso exemplar da existência de um sistema de pós-graduação avançado, produtivo e formador dos recursos humanos e científicos que têm alimentado o crescimento econômico ea diversificação social do país, justaposto a situações dramáticas quanto ao estado do ensino em outros níveis, especialmente no setor público.

Desta forma, o governo federal brasileiro tem feito um esforço enorme em direção ao aumento das matrículas em todos os níveis do sistema educacional brasileiro. No ensino fundamental, que atende a alunos com idade entre 7 e 14 anos, 0 índice de matrículas passou de 84\% em 1994 para $96 \%$ em 1999.

No ensino médio houve sal to maior, com um crescimento de $57 \%$ nas matrículas, no período 1994-99. No ensino fundamental, $90,9 \%$ dos alunos foram matriculados nas escolas públicas e 9,1\% em estabelecimentos privados. No ensino médio, $84,2 \%$ das matrículas estão no setor público, enquanto $15,8 \%$, nas escolas privadas.

0 oposto ocorre no ensino superior, em que $37,9 \%$ estão no setor público, enquanto $62,1 \%$ das matrículas pertencem ao setor privado. A taxa de crescimento do ensino superior, entre 1994 e 1999, foi de 28\%. São indicadores notáveis de envolvimento da população com o sistema educacional formal.

A pesar disto, apenas $11 \%$ da população com idade entre 19 e 24 anos, tecnicamente escolarizável pelo ensino superior, está nos bancos universitários. Taxa que põe o B rasil muito abaixo de países como Estados Unidos, França, Coréia, J apão, A rgentina, M éxico, U ruguai, entre outros.

Todavia, simultaneamente à consolidação da onda expansionista, surgem complexos problemas relacionados à qualidade do ensino e ao desenho das instituições públicas e privadas provedoras desse bem essencial ao desenvolvimento e à democracia.

É o caso, por exemplo, de recentes denúncias envolvendo elaboração de pareceres da Câmara de Ensino Superior, seção do Consel ho Nacional de Educação, favoráveis à criação de novas faculdades e 
centros universitários privados no país, sem a qualificação exigida por lei. O u seja, é preciso contemplar as íntimas relações entre qualidade e quantidade, para realmente avaliar as realizações nesse campo.

A questão mais abrangente, envolvendo decisões sobre a educação nacional, está historicamente ligada à postura assumida pelas elites brasileiras. Diferentemente do que ocorreu em países como Estados Unidos, França, A lemanha, Japão e Coréia - entre outros -, aqui as elites nunca encararam a educação geral como um bem estratégico, como um componente essencial para a consolidação de uma sociedade democrática e com projetos de poder no quadro internacional.

E m parte, isto é devido a nossa herança colonial, na qual I greja e latifundiários controlaram o acesso à educação básica e, em particular, 0 acesso à educação de nível superior. Educação sempre foi vista, pelas elites econômicas e políticas, como uma deferência pessoal e de classe.

O u seja, uma maneira de conferir status diferenciados a cidadãos teoricamente iguais. R enda, propriedade e al to nível de educação sempre estiveram aliados no B rasil, como forma de distinguir pessoas e grupos sociais. A natureza de nosso elitismo antidemocrático sempre esteve fortemente arraigada nesse preconceito. Foi útil aos donos do poder, foi péssimo para a democracia que poderíamos ter consolidado há muito.

Recentemente, de modo especial a partir dos anos 70 , com o dinamismo da economia internacional e a incorporação do projeto de poder brasileiro, baseado na matriz militar-burocrática, ficou evidenciada a debilidade de nosso sistema educacional, em todos os níveis.

Começou um enorme esforço: redirecionamento de investimentos, programas de formação de docentes, fortal ecimento do sistema federal de ensino superior e, principalmente, a verdadeira criação de um sistema de pós-graduação, liderado pelo CN PQ/M CT e pela Capes/M EC.

$O$ utros programas de fomento à pesquisa e à pós-graduação foram criados. 0 Brasil conseguiu, a partir daí, ser alçado à condição de país latino-americano possuidor do melhor sistema de pós-graduação. Os efeitos desse gerenciamento logo puderam ser constatados, por meio de enormes progressos em ciência e tecnologia absorvidos por empresas e centros de pesquisa em todo o país.

Todavia, persistem graves problemas, especial menteligados à área do ensino superior público. Destaca-se a falta de decisão do governo federal diante de suas responsabilidades como mantenedor de um 
subsistema até agora eficaz e o mais produtivo em ciência e tecnologia no país.

A receita do setor privado de ensino superior, em 1999, foi de cerca de $\mathrm{R} \$ 5$ bilhões, em torno de $10 \%$ a mais do que o montante do orçamento executado por aproximadamente 55 instituições de ensino superior federal, mantido o instituto da gratuidade geral aos al unos.

É escasso o recurso, sabendo-se que em nível internacional, por exemplo, a Intel investiu cerca de US\$ 20 bilhões em pesquisa e desenvolvimento de seus laboratórios em 1999. Enfim, estamos diante de um sistema al tamente complexo, exigindo audácia e criatividade. Não haverá democracia, nem desenvolvimento econômico e social, sem um sistema nacional de educação universal e eficiente. U ma batalha que mal começou.

\section{Brasil cria a Universidade Pública Virtual}

Está por ser criada, por iniciativa do Executivo, a Universidade Pública Virtual do B rasil. A criação dessa universidade está integrada ao projeto educacional estratégico de nosso país. Será localizada no âmbito das universidades públicas existentes, federais e estaduais, e será aberta a usuários do setor privado, em condições distintas.

A inspiração original tem uma dupla raiz: a absorção de tecnologias de informação já disponíveis para utilização no processo educacional, bem como a expansão da capacidade já instal ada nas instituições públicas de ensino superior.

Hoje, a produção real está cada vez mais dependente dos fluxos de informação e conhecimento que superam os limites físicos das unidades universitárias. A disponibilidade de novos meios tecnológicos possibilitará, conseqüentemente, a multiplicação dos ef eitos do processo educativo de natureza presencial. Ou seja, a capacidade de gerar conhecimento excede a capacidade física dos docentes; daí que sua presença material não é fator determinante para o processo educativo.

A institucionalização da universidade pública virtual brasilei ra está nos moldes da sociedade da informação. A s principais universidades do país, ao longo dos anos 90 , começaram a implantar projetos de ensino à distância. 0 conjunto de esforços isolados produziu empreendimentos que não estão em rede, pois a cooperação inter-institucional tem estado 
ausente. A presente iniciativa visa superar esse obstáculo, integrando as diversas experiências em um sistema organicamente estruturado. A ssim, desde 1998 começam a surgir projetos de consórcios para a produção compartilhada de cursos em diferentes campos do conhecimento, como é o caso da recentemente criada U niversidade Virtual do Centro-O este (Univir-C O). Sob a mesma orientação, a partir de 1999, diversas universidades públicas constituem a U niR ede. São 56 instituições públicas trabalhando para aumentar a capacidade de formação de alunos, em vários campos do conhecimento. 0 suporte técnico estará baseado na capacidade da Internet II, por sua possibilidade de integrar produção de conhecimento em rede nacional.

Diante da crise de identidade que assol a a A mérica L atina, baseada na expansão de processos globalizadores, a experiência busca integrar a produção do subcontinente americano, com vistas à recuperação de posicionamentos soberanos e de val orização de nossa experiência cul tural comum. Também é uma forma explícita de evitar que o B rasil e a A mérica Latina sejam "africanizadas" ou transformadas em simples entreposto de mercadorias e conhecimentos.

\section{Obscurantismo domina universidades brasileiras}

Contrastando com essas iniciativas que procuram atender ao nosso histórico no campo educacional por meio da absorção denovas tecnologias funcionando em rede, o quadro político universitário brasileiro atravessa mais um momento acidentado. A Igumas universidades públicas, estaduais (São Paulo) e federais, em vários estados, estiveram recentemente paralisadas. A reitoria da Universidade de São Paulo (USP) foi sitiada por estudantes e funcionários. 0 reitor ficou asilado em sua sala de mando durante al guns dias.

Os professores das universidades federais estão se movimentando em busca de um reajuste de $63 \%$ nos seus salários básicos. 0 governo federal resiste, alegando que tem oferecido a $G$ ratificação por $A$ tividade Docente (GED), pelo segundo ano consecutivo; no corrente ano houve, efetivamente, um aumento de $30 \%$ na gratificação.

O corre que essa gratificação atinge os mais titulados, os mais produtivos e os mais assíduos. Fato que não é universal entre os professores do sistema público federal. Daí a revolta, em especial, de 
um pequeno contingente, cerca de $30 \%$ dos docentes, que não recebe a GED integralmente. Em termos quantitativos, a GED pode atingir até $30 \%$ do salário de um professor titular em dedicação exclusiva.

O M inistério de Educação não conseguiu implementar seu projeto de autonomia universitária, baseado no modelo inglês implantado por $M$ argareth Tatcher. Houve resistência dos dirigentes universitários e do próprio movimento docente. Este, por meio do sindicato nacional da categoria (A ndes), resistiu bravamente a al gumas das linhas essenciais do projeto original.

A resistência da Andes - na gestão de Renato de Oliveira, professor da U niversidade F ederal do Rio Grande do Sul - baseou-se na defesa de certas bandeiras clássicas no campo de batalha da educação nacional. Contudo, no último mês de junho, com comparecimento de apenas 32\% dos associados nacionais, a diretoria de O liveira (1998-2000) perdeu as el eições para a oposição ul tra-esquerdista, hegemonizada pelo Partido Socialista dos Trabalhadores Unificados (PSTU) e alas revolucionárias do PT.

Esse grupo se nega a dialogar com o ministro Paulo R enato Souza, da E ducação, bem como com outros órgãos governamentais. Para ele, a autonomia universitária está assegurada pela vigência automática do artigo 207 da Constituição Federal de 1988. Não seria necessária nenhuma legisl ação complementar para que o mesmo dispositivo se tornasse efetiva realidade. $\mathrm{Na}$ prática, isso significa paralisia da negociação, impossibilidade de diálogo e acirramento político nas relações entre 0 sindicato nacional dos docentes ( 66 mil associados) e o governo federal.

Para a nova direção da A ndes, o que conta é a oposição sistemática ao governo de Fernando Henrique Cardoso. A nuncia-se uma guerra longa de desgaste do governo nas universidades brasileiras.

De outro lado, paral ela e eficazmente, o governo vai desenvolvendo complexa engenharia política. Ela envolve os dirigentes universitários (reitores) e a sua base parlamentar no Congresso Nacional. Está em pauta na Comissão de Trabal ho, na Câmara F ederal, o projeto que cria a figura do "empregado público", substituindo a atual figura do "funcionário público". 0 projeto já foi aprovado pelo Senado. No ensino superior, isso implica que, doravante, qualquer professor ou administrador seria contratado pelo regime prescrito pela Consolidação das L eis do Trabal ho (CLT) e não pelo regime estatutário, vigente após 1988. A lém disso, há 
uma Proposta de Emenda Constitucional (PEC), do Executivo, junto à Comissão do Trabal ho da Câmara Federal, mas ela ainda não entrou na pauta. Essa proposta possibilita a criação de sindicatos por universi dades, inviabilizando sindicatos de âmbito nacional, como a Andes. M atéria combustível que certamente, quando entrar na pauta, provocará terríveis reações.

Com referência à Gratificação por A tividade D ocente (GED), já em seu segundo ano de vigência, há propostas de emenda à $M$ edida Provisória 2020 que regulamenta a matéria, de autoria da última diretoria da A ndes (1998-2000). A s propostas visam garantir $100 \%$ da gratificação aos professores aposentados. Para tratar do assunto e encaminhar a demanda dos aposentados, a atual diretoria da A ndes teria de negociar, dial ogando intensamente com o Executivo e o Congresso $\mathrm{N}$ acional. $\mathrm{M}$ as esta já anunciou que não fará tal coisa, o que, paradoxalmente, deve aumentar a pressão dos professores aposentados sobre o Congresso e 0 Executivo.

No quadro da teoria dos jogos, fica evidente que as perdas serão mútuas, já que a paralisia de negociações leva a um empate técnico. $\mathrm{E}$ em situação de empate, todos perdem, pois a política não éjogo de futebol, no qual o empate confere um ponto para cada time.

No conjunto dos fatos, fica evidente que a universidade pública brasileira tem todas as condições de sair prejudicada diante da opinião pública e dos concorrentes. G reves selvagens, com metas indefinidas e inviáveis, bem como negativa de negociações com os organismos oficiais, tendem a favorecer as competidoras privadas. É quando a ultra-esquerda universitária surge como a maior aliada dos setores privatistas, que não querem um setor público de ensino superior eficaz e de alta qualidade.

\section{Qualidade e acesso à universidade}

$\mathrm{N}$ a medida em que a nova ordem econômica e social depende da general ização de um processo educacional, permanente e de qualidade, é justo considerar o conjunto de fatores que determinam o baixo acesso ao ensino superior no B rasil, atualmente.

Dados da U nesco e do Instituto $\mathrm{N}$ acional de Estudos e Pesquisas Educacionais (Inep/MEC) apontam para flagrantes desequilíbrios internacionais. A penas 11,3\% da população brasileira, entre 19 e 24 anos, 
está matriculada em instituições de ensino superior, número muitas vezes menor do que apresentam Estados Unidos (81\%), França $(51 \%)$, A rgentina (36\%), U ruguai (29\%), Chile (28\%), Colômbia (17\%), M éxico $(14 \%)$, por exemplo.

0 desenvolvimento global izado de nossos dias está profundamente ancorado em matrizes de produção que requerem conhecimento científico e informação. M esmo em conjunturas de franca abertura econômica como a que atravessa o Brasil hoje -, com importação de modelos tecnológicos provocados pela privatização das estatais e entrada de grandes multinacionais que não dependem da produção científica brasileira, somente com alta educação será possível participar criativamente desse processo. Uma indicação dessa necessidade está na prevista nacionalização de componentes e insumos industrializados, que estão presentes em alguns setores estratégicos como telecomunicações e produção automotiva, sediados no Brasil. Assim, segundo J osé K opfer (G azeta M ercantil, 23/02/00), relatando pesquisa da FGVRJ, dirigida pela economista Virene Roxo $M$ atesco, o investimento em inovação e capacitação tecnológica de multinacionais que operam no B rasil alcança, em média, 2,2\% do faturamento, sendo de até 4,5\% nas grandes corporações.

O planejamento dessas corporações prevêinvestimentos superiores às taxas históricas, a partir de 2000 . A pesquisa foi aplicada em 85 empresas multinacionais no Brasil. Em seu conjunto, essas empresas representam 5\% do PIB global brasileiro e 15\% do PIB industrial. Os investimentos verificados no B rasil são compatíveis com os feitos pelas corporações globais em outros mercados regionais. Eles visam, sobretudo, adaptar produtos e processos. Em $40 \%$ dos casos, entretanto, as empresas desenvolvem produtos diferentes dos produzidos na matriz. 0 destino da produção final das corporações globalizadas tem sido, preferencialmente, o $\mathrm{M}$ ercosul.

0 cenário indica que a abertura econômica, apesar dos traumas e reorganizações abruptas da produção, não necessariamente impede 0 desenvolvimento de inovações tecnológicas no Brasil. Os grandes exemplos estão na conhecida E mbraer, no setor de hidrogeração da alemã Siemens, cujos centros de excel ência mundial estão local izados no B rasil e no pólo cerâmico de Santa Catarina. N esse caso, houve aliança bemsucedida com produtores de insumos e design italianos. 
G rande parte desse padrão de desenvol vimento associado, visando a mercados externos, não depende só da disponibilidade de força de trabalho com educação de nível superior. M as ela é fundamental no desenho de estratégias mais sofisticadas e de qualidade competitiva. A Itália, a partir de 1950, aderiu a esse modelo, sustentando seu crescimento e sua participação no mercado mundial na estrutura de empresas de porte médio, extensão do envolvimento familiar, com êxito absoluto, a ponto de configurar o que foi conhecido como o milagre italiano.

0 B rasil tem feito um esforço notável em direção à ampliação de oferta de ensino superior. A partir de 574 mil vagas of erecidas pelo sistema público e privado em 1994, evoluímos para 766 mil vagas em 1998. A taxa de crescimento geral, no período, foi de $35 \%$. A s instituições públicas cresceram $16 \%$ e as privadas $44 \%$. Todavia, considerado o número teórico de pretendentes ao ensino superior, graduados do ensino médio, temos em 2000 um déficit de cerca de 2 milhões de vagas!

D e outro lado, a qualidade da educação universitária ofertada tem sido objeto de muita polêmica. Mais uma vez, o Estado, por meio do Consel ho $\mathrm{N}$ acional deE ducação (CNE), tem revel ado enormes fraquezas. O Provão e o Sistema Nacional de Avaliação das Universidades têm demonstrado o caráter puramente comercial e desqualificado de centros universitários privados e públicos. U m duro desafio a ser enfrentado.

Progridem, felizmente, operações lideradas pelo M inistério de Ciência e Tecnologia com o objetivo de implementar a utilização dos fundos setoriais para o financiamento de pesquisas (petróleo, telecomunicações, energia, informática). Os fundos deverão favorecer os centros de excelência em pesquisa, hoje concentrada em cerca de $85 \%$ dos casos nas universidades públicas, federais e estaduais. Um paradoxo que ilustra as dificuldades de gestão do sistema universitário brasileiro: as universidades públicas têm apenas $26 \%$ das matrículas, enquanto $74 \%$ estão com as privadas. Sendo o desenvol vimento da ciência e tecnologia o resultado de uma profunda associação entre ensino e pesquisa, algo de dramático está explicitado pelos dados. Nessa linha, torna-se visível que, ao maior número de matrículas dos centros universitários privados, não tem correspondido similar esforço de pesquisa. 
Burocracia e evasão de talentos

0 Censo Demográfico 2000 do Instituto B rasileiro de G eografia e Estatística (IBGE) foi iniciado em agosto. A partir dos anos 80, como atestado pelo Censo de 1991, há um êxodo crescente de brasileiros ao exterior, num total hoje estimado em 2 milhões.

Esse fato é central para a quebra do imaginário em que o B rasil é construído como país de atração permanente de estrangeiros. País de imigrantes, agora tendemos a ser um país de migrantes. Há muitas razões para isso. A década economicamente perdida de 80 , a lenta retomada do crescimento econômico, com crescente desemprego devido à intensa modernização da produção e a outras questões de ordem gerencial que afetam a condução de instituições públicas.

$\mathrm{Na}$ A mérica do Sul, o fenômeno afeta a A rgentina, desde a década de 1970, de modo massivo. Lá, como aqui agora, uma das razões que extrapolam os fatores já mencionados é o modo negativo como se dão as relações entre setores de ponta da economia, dimensão exaltada no presente contexto de globalização e absorção acelerada de tecnologia. 0 nó da questão pode ser exemplificado pela ausência de sinergia entre a produção de conhecimentos científicos e tecnológicos nos centros universitários públicos e privados e as empresas. 0 conhecimento estabelecido serve para difusão, não necessariamente para incorporação produtiva, sob o controle de empresas públicas ou privadas.

U m exemplo marcante dessa falta de sinergia está no acompanhamento do Projeto $\mathrm{G}$ enoma, desenvolvido com êxito total por pesquisadores de várias universidades paulistas, sob patrocínio da Fundação de A mparo à Pesquisa do Estado de São Paulo (Fapesp) e do Fundo de D efesa da Citricultura (Fundecitrus), tendo consumido US\$ 15 milhões. 0 projeto decifrou o código genético completo de uma praga agrícola (o amarelinho dos cítricos) que causa prejuízo de até US\$100 milhões por ano à agricultura, por falta de condições, não só econômicas, para transformar o conhecimento obtido em tecnologia.

U m dos coordenadores do projeto, o biólogo Fernando Reinach, professor da USP, afirma (F ol ha de São Paulo, 18/06/00) que há razões de ordem administrativa impedindo a internal ização da cooperação entre as universidades públicas e as empresas interessadas em produzir tecnologias aplicáveis. Um dos problemas é a impossibilidade de 
remuneração dos professores que participam do projeto científico, dados os limites dos contratos de dedicação exclusiva à universidade pública.

$M$ ais um paradoxo, no qual o êxito científico que repousa sobre a dedicação acadêmica é punido pela limitação do sistema de gestão. Razões assim favorecem a expansão do setor privado na educação superior do Brasil. Esse conjunto de fatos, aliado às baixas taxas de crescimento econômico, incentiva a saída de brasileiros tal entosos para o exterior.

\section{Democracia e pessimismo profissional}

Em simpósio da 52a reunião anual da SB PC, na U niversidade de B rasília, sob a coordenação de B enício Schmidt, contando com a presença dos professores Hélgio Trindade e Eli Pinto, da U niversidade F ederal do Rio Grande do Sul, foi realizada uma discussão sobre o significado da "democracia participativa nas condições contemporâneas".

0 tema é indigesto, não muito estudado no B rasil, dando margem a grande confusões conceituais. Além disto, o debate se torna difícil entre cientistas sociais nacionais, dada a falta de tradição empírica da área. A mai or parte dos estudos em sociologia e política, principalmente, não apresenta referentes empíricos, sobre os quais poderiam ser estabelecidas as bases de um debate real, validado.

Outras dificuldades estão na precoce e artificial politização dos poucos conhecimentos disponíveis. Tratar de democracia no B rasil, antes de mais nada, hoje, é posicionar-se contra ou a favor do pretenso neoliberalismo do governo de Fernando Henrique Cardoso.

Com isto, é construída uma barreira que impede o reconhecimento de nossos avanços democráticos, especialmente desde a Constituinte de 1988. N ela, o país consagrou al guns institutos jurídicos, como o mandado de injunção, pouquíssimo utilizado pelos cidadãos, e que visa garantir acesso a bens e serviços públicos definidos como universais, a exemplo da educação el ementar.

Outros casos surgem ilustrando esses avanços, como a administração compartilhada entre o Estado e outros agentes sociais sindicatos, centrais sindicais e entidades empresariais ou organizações não-governamentais. A política de assistência social, de saúde pública, os programas de formação e qualificação profissional dos trabal hadores, as políticas educacionais, a política de reforma agrária são exemplos 
candentes de que já saímos de uma fase embrionária da democracia representativa para a democracia mais participativa.

0 Estado brasileiro atual tem sustentado programas extensos de políticas sociais compensatórias, considerados entre os maiores do mundo, como éo caso da assistência a idosos e deficientes físicos, com orçamento de cerca de $\mathrm{R} \$ 10$ bilhões anuais, maior do que os gastos do $M$ inistério de E ducação com todo o sistema federal de ensino superior público, que é hoje cerca de $R \$ 7$ bilhões anual mente.

0 que está em jogo, daqui por diante, é o desafio do aprofundamento desses programas amplamente democráticos, tornando-os mais eficientes e transparentes. Já ultrapassamos o momento de estabelecer as bases mínimas da governabilidade, que se define pela possibilidade de haver força política para governar. Estamos agora em território pertinente à governança, que se traduz por transparência e responsabilização total dos governantes (accountability).

Todavia, essas implicações esbarram no fato de que 0 debate público entre intelectuais e a imprensa continua sendo comandado por conceitos al go fora do lugar, prejudicando o entendimento do que se passa no país e impedindo a formulação mais correta de projetos para o futuro. 0 pessimismo contaminado das análises tem como fonte primordial a incapacidade teórica e metodológica de grande parte dos intelectuais.

$\mathrm{Na}$ verdade, a negatividade dos argumentos não reflete, necessariamente, a existência de um exercício crítico. Os dados não têm sido contemplados, bem como as al ternativas historicamente oferecidas não têm sido avaliadas. Cria-se um ambiente pouco propício ao debate e a considerações de possíveis históricos.

Diante das intransigências de discursos e práticas brasileiras, é sempre bom fazer considerações comparativas, tendo a A mérica L atina como ponto de referência. Com os movimentos de integração política e dos mercados econômicos, a $A$ mérica $L$ atina ressurge para o $B$ rasil como uma referência importante e necessária.

A s elites políticas brasileiras têm sido, e logicamente serão, traídas pelas costumeiras abordagens de curto prazo e de pouca abrangência analítica. A urgência de várias crises históricas acumuladas, de origem política e econômica, é uma das determinantes da pressa em resolver problemas complexos com estratégias simplórias. 
O B rasil embarcou inexoravelmente nas políticas de ajuste estrutural, determinadas pelo $\mathrm{FMI}$ e pelo $\mathrm{B}$ anco $\mathrm{M}$ undial. A final, uma contingência histórica. Todavia, isto não deveria ter perturbado a visão das elites sobre questões que não podem receber um tratamento padronizado, segundo os ditames das agências internacionais. É o que indicam as recentes crises institucionais que ameaçam profundamente a governabilidade de muitos países latino-americanos.

Eleições fraudadas no Peru, com Fujimori pretendendo a eternização, apesar de seus ganhos já consolidados na luta contra a guerrilha e a inflação e das pressões internas e externas. Estado de sítio na B olívia, com recrudescimento da violência política e militar, sempre subjacente à política local. Tentativa presidencial de fazer um referendo na Colômbia, que resultaria na elaboração de uma nova Constituição, com el eição de novo Congresso N acional. A Constituição de 1991 seria revogada na prática. É bom frisar que, hoje, o Estado colombiano controla um pouco mais da metade do território nacional, tão-somente!

De outro lado, Lagos enfrenta a recessão chilena e a "questão M apuche". A recessão se deve à perda de val or de produtos estratégicos de exportação. A questão envolvendo os índios Mapuche reside na tentativa de formar, dentro do Estado chileno, uma outra nação. 0 organismo político ibero-americano é historicamente antagônico ao respeito das nacionalidades. Procuramos sempre, devido à herança portuguesa e espanhola, justificada pelo positivismo e pelo pensamento católico-republicano, sublimar as diferenças nacionais dentro dos Estados. A opressão política e cultural bem como o extermínio de povos inteiros são nossas preferências.

0 quadro latino-americano atual tem algo a sugerir às elites brasileiras. A qui também os povos indígenas - que desejam a organização de suas nações dentro do Estado brasileiro, mas diferenciadas - tentam conquistar espaços políticos. A qui, também, a pressão por educação superior pública e de qualidade tem sido buscada pela população em urbanização crescente. A qui, também, a proteção aos velhos e desempregados tem sido motivo de batalhas políticas. No entanto, aqui, como no Peru, na Colômbia, na Bolívia e no Chile, as elites políticas estratégicas centralizam suas atenções no ajuste macroeconômico e nas regras de sua própria sucessão. 
A qui, como acolá, a realidade em constante mutação, com 0 aumento da pressão por demandas urbanas e de cidadania (educação, segurança social, emprego), é tratada com arrogância, como se fosse um problema que terá solução automática, a partir do ajuste das contas públicas. Isto não é verdade, pois não há comprovação empírica!

A o aumento dos gastos sociais no Brasil, por exemplo, não tem havido correspondência, na mesma proporção, da diminuição das linhas de pobreza. 0 aumento da of erta de vagas no ensino superior, basicamente no setor privado, não tem tido correspondência necessária no aumento de qualidade da oferta, gerando mel hores condições de competitividade ao país.

Está ausente uma estratégia estatal de remodelação das agências intermediárias que são responsáveis pel o of erecimento de bens e serviços que tenham por função disciplinar os fatores econômicos e sociais que garantiriam a reprodução democrática do sistema social.

No Peru, nos últimos 15 anos, estima-se em 25 mil o número de vítimas da guerra civil entre o Estado e a guerrilha. D este total, cerca de 5 mil são militares das Forças A rmadas peruanas; outros 5 mil são vítimas passivas, membros da população em geral, e cerca de 15 mil são jovens em idade universitária, militantes das diversas facções guerrilheiras. Pela baixa of erta de oportunidades, principal mente educação e empregos, os jovens são atraídos pela guerrilha, o que não deixa de ser uma forma de engajamento empregatício. E m geral, esses jovens são inexoravel mente dizimados no âmbito de uma guerra mesclada pela economia da droga. A sociedade peruana, como as demais citadas, encontra-se com o tecido social esgarçado. Difícil será a reconstituição dos padrões mínimos de sociabilidade, como ponto de partida para uma convivência pacífica e criativa.

Essas incidências são alertas às elites políticas brasileiras, provincianas e arrogantes, centradas no próprio umbigo. A palha vai secando, uma faísca, ou várias, pode surgir. Inesperadamente? Só para os cultivadores da auto-suficiência!

Em pleno transcurso do projeto rumo às metas do ajuste estrutural, a A mérica L atina volta a ser objeto central das atenções. $A$ estabilidade macroeconômica tem sido fortemente abalada por recentes acontecimentos internacionais, como aquel es decorrentes da queda das principais 
bolsas de valores do mundo, todas abarcando capitais relacionados a grandes investimentos na A mérica L atina.

Outros acontecimentos são de ordem interna. A fragilidade dos sistemas de representação democrática fica cada vez mais evidenciada na situação dramática enfrentada por países como Colômbia, Bolívia, Paraguai, Peru e Venezuela.

$\mathrm{N}$ ão por acaso, a presença maciça da economia da droga nesses países torna difícil a estruturação de um sistema político representativo, ancorado nos clássicos mecanismos de consulta e sucessão política.

$N$ esse quadro, a plena internacional ização dos fluxos econômicos ajuda, ainda, a ressal tar a precariedade do sistema de relações sociais e políticas. $N$ a verdade, a A mérica $L$ atina convive em ambientes de muitas transformações simultâneas, sem ter ainda resolvido alguns dos seus fundamentos de infra-estrutura.

A ssim, as transformações econômicas têm abalado, principalmente, o sistema de organização do trabal ho e de suas representações sindicais e políticas. $M$ ais recentemente, depois das eleições de 7 de maio para governador de Buenos Aires, a A rgentina tem experimentado grandes convul sões sociais de massa, incluindo manifestações de xenofobia antibrasileiras a partir da penetração comercial do nosso país naquele território. A s reformas estruturais, especial mente a relativa à flexibilização de leis trabal histas e ao combate às formas de evasão fiscal, têm sido objeto de encarniçadas lutas no Congresso Nacional e nas ruas. A pressão sobre as relações entre a moeda nacional e o dólar norte-americano é um grave indicador dessa instabilidade.

0 quadro geral é de imensas dificuldades. Do ponto de vista das elites políticas estratégicas, parece claro que os executivos latinoamericanos terão de conviver cada vez mais com altos níveis de conflitos políticos e sociais, baseados que estão na agudização do que se chamaria (antiga, mas não tão remotamente) de luta de classes.

Nesse sentido, a vulgarização de certos episódios envolvendo pressões populares, geralmente muito bem organizadas por atores sociais complexos e sofisticados, como o M ovimento dos Trabal hadores Rurais Sem Terra (M ST) no Brasil, ajuda a naturalizar o novo tipo de conflito. Há um desafio aos sistemas políticos em vigor no continente. A pura repressão, em condições de aprofundamento da democracia repre- 
sentativa, é inaceitável. A solução parece estar na obediência aos velhos ditames da social-democracia européia em períodos de grande conflito político e social. N egociar, operar, corrigir rumos, na expectativa de que as grandes estruturas macroeconômicas comecem um novo ciclo de acumulação e possibilitem melhor distribuição do produto gerado.

A xioma derivado das teorias de desenvolvimento, sem criação de excedente econômico não há civilização. Para debater esse tortuoso processo de mudanças, em ambiente de grande pressão social e instabilidade, realizou-se em Buenos Aires em maio de 2000 o III Congresso L atino-americano de Sociologia do Trabalho. Entre muitos temas abrangentes e centrados na problemática criada pel o grande aj uste das estruturas trabal histas, como os sindicatos, estão as implicações das modificações trazidas pela internacionalização dos mercados latinoamericanos de trabalho. Os resultados e avaliações não foram nada al vissareiros, devido à fal ta de al ternativas políticas disponíveis.

Tanto especial istas, como agentes mobilizadores e sindicalistas, constataram as enormes dificuldades em oferecer caminhos distintos às políticas de ajuste estrutural comandadas pelas finanças internacionais, a partir de situações de déficits fiscais históricos carregados pel os Estados na A mérica Latina. 0 rompimento com a cadeia de decisões que condicionaram as políticas macroeconômicas na região não se apresenta como algo fácil de ser conseguido. Em geral, por comodismo ou fal ta de criatividade teórica, aceitam-se as circunstâncias históricas como passageiras. Somente uma nova onda de crescimento econômico, com ajuste fiscal crescente, possi bilitará a elaboração de al ternativas globais. É o velho "etapismo", que marcou a convivência política e intelectual entre o estrutural ismo cepalino e as perspectivas embasadas no marxismo na A mérica $L$ atina. Diante do Estado enfraquecido, verdadeiro L eviatã encurralado, começam a faltar alternativas politicamente viáveis aos setores mais progressistas no subcontinente. Dessa forma, ressurgem ondas de moral ismo, fazendo crer que o aperfeiçoamento dos mecanismos legais de controle da administração pública, ainda que necessários e essenciais, serão suficientes para estabelecer novos patamares e horizontes históricos.

Nesse panorama, parece vital ter em perspectiva as transformações históricas do Estado, para que a imaginação sociológica e política possa ser exercida. A questão é relevante especialmente porque diz 
respeito ao enfrentamento das atuais debilidades estatais encaradas desde a origem da capacidade de extração fiscal, justamente aquele que possi bilita a expansão ou retração das funções reprodutivas do Estado.

0 Estado moderno nasce com as monarquias nacionais européias, em luta contra o feudalismo. No período que vai do século $X V$ ao século $X V I I I$, sob a liderança das monarquias absolutistas, dois elementos foram historicamente essenciais para a formação do Estado moderno que conhecemos: a criação de impostos e a formação de corpos militares disciplinados e leais aos soberanos. Estes, respal dados no direito divino, sob a égide do cristianismo, num quadro de grande violência, tinham seus projetos de central ização do poder respal dados pela I greja romana como instituição política universal.

0 processo de formação do Estado moderno foi extremamente cruel. A Inglaterra enfrentou sérias rebeliões regionais entre os séculos $X V$ e XVI. No século XVII houve efetiva concentração de poder na mãos dos Stuart, ainda que com enorme penetração do que conhecemos como relações capitalistas de produção, a partir da aliança entre proprietários de terras privatizadas (enclosures) e classes comerciais urbanas. Nunca houve um período maior do que dez anos sem que a Inglaterra conhecesse violência e turbulência social até a restauração de seu reinado. A Guerra Civil na Inglaterra (1640-1660), passando pelo protetorado de Cromwell (1653-1658), foi palco de lutas centradas na questão da terra, conformando o poder político organizado posteriormente. Outro exemplo dramático, na perspectiva de centralização de poderes dispersos sob o manto dos soberanos, é dado pela França. Durante 0 século XVI, a França experimentou sangrentas guerras religiosas, que colocavam em disputa prerrogativas reais estabel ecidas contra aspirações de liberdade regional. 0 século XVII francês conheceu violentas resistências à coroa, que demandava crescentes taxas e impostos à população, destruindo militarmente as oposições locais. Ainda que houvesse forte resistência popular à convocação da população ao serviço militar e medidas que forçavam a distribuição de grãos às cidades, as formas mais importantes de luta contra a central ização dos poderes estatais vieram sempre sob o título de resistência aos tributos, impostos e taxas. Impostos e exércitos sempre foram os recursos essenciais de poder para a criação do Estado moderno. A resistência à tributação das diversas classes sociais levava ao fortal ecimento militar, e vice-versa. Em 1500, a 
Europa abrigava cerca de quinhentas unidades políticas relativamente autônomas, que foram reduzidas a vinte Estados independentes em 1900; uma operação de grandes dimensões.

0 caminho ocidental para o estabel ecimento do Estado moderno, na verdade, inicia-se no século XVII com a Revolução Inglesa, firma suas bases políticas com a sublevação das colônias britânicas (1775), seguida da Declaração de Independência dos Estados U nidos (1776) e culmina com a R evolução Francesa (1789). Outras matrizes são criadas, com códigos universais de direitos não necessariamente centrados no indivíduo, mas na coletividade. É o caso das revoluções do século XX no M éxico, na Rússia e na C hina.

Em qualquer perspectiva disponível, a implantação do Estado moderno tem como fulcros a central ização do poder, extraído de múl tiplas unidades de controle territorial por meios militares e tributários, bem como o estabel ecimento da supremacia de um direito universal objetivo sobre todos os interesses e direitos particulares. A o longo destes dois últimos séculos, o Estado que conhecemos hoje é a resultante de uma grande e incomparável invenção social e política. Ele tem sido construído ao redor de uma enorme tensão entre as aspirações individualistas de pessoas e grupos de interesse e as propostas de suporte coletivo. A recente falência dos modelos políticos inscrita sob o socialismo real, liderados pela experiência soviética, sinal iza o fim de uma era, mas fortalece a existência de um desafio teórico e prático não resolvido, desde os primórdios da modernidade que nasce com a $\mathrm{D}$ eclaração de Independência dos Estados Unidos.

0 desafio central do Estado moderno está local izado na conciliação entre 0 individual e o coletivo. A crescente transformação das relações sociais, sob a égide da universalização das formas mercantis de produção em que o capital ismo vai se tornando hegemônico em todo planeta, torna evidente que nem todos os homens e culturas estão disponíveis para seguir as conseqüências necessárias de uma ordem social e política na qual o elemento eficiente édado pelo êxito da iniciativa e atividade pessoal. U m sintoma claro dessa contradição está posto pel o fato contemporâneo da existência de uma riqueza jamais acumulada pela humanidade, convivendo com formas predatórias e desumanas de pobreza e discriminação general izadas em todo o globo, em todos os países, inclusive nos mais ricos. 
Isto tem tornado ainda mais agudo o desafio deste fim de século. A existência massiva da pobreza e exclusão, ao lado de enorme e inusitada riqueza, implica a necessidade de intervenção do Estado no próprio circuito mais profundo das relações sociais e econômicas cotidianas. Ocorre, para agravar 0 eterno desafio às teses fundadoras do Estado moderno democrático, que este mesmo E stado se encontra - hoje - desaparel hado e incapaz de uma intervenção que seja eficiente e democrática.

A imperícia estatal se revela na sua ineficiência como provedor de bens públicos essenciais, como serviços de educação, proteção social, educação e segurança, bem como na sua debilidade, como agente de ordem pública universal, para garantir o exercício dos direitos plenos de natureza individual e coletiva de seus cidadãos. $\mathrm{N}$ a verdade, $\mathrm{O}$ Estado moderno, ao fim do século XX, está indicando o fim de um ciclo, no qual ele perde o monopólio da representação dos interesses coletivos, da força e da violência sistêmica e da iniciativa de políticas de interesse universal. A recente Conferência da OMC em Seattle (EUA), onde organizações não-governamentais de vários países praticamente impediram as deliberações dos Estados nacionais, bem exemplifica o quadro atual de impasses.

Abstract

In the educational sphere, Brazil also presents old dualisms that support the national society. There is the remarkable case of an advanced post-graduation system, which is productive and forms human and scientific resources, juxtaposed with dramatic situations related to the state of education in other levels. As a result, the adbption of policies of enrolment increase in all levels ocaurs isolated from corresponding measures related to the quality of education. In the public higher education area the deformations are really something to cause worry. The reflection proposed in this article is based on two premises: the Brazilian elites have never considered education as an essential component to consolidate a democratic society with projects of power in the intemational scenery; together with the vacancy increase, the guarantee of quality is a strategical variable to determine the future possibilities of the national potentials development.

Key words: university expansion; democracy; quality. 
L 